\title{
O ESQUECIMENTO APRESENTADO EM O FEMININO E O SAGRADO, DE JULIA KRISTEVA E CATHERINE CLÉMENT, COMO PARTE DA CONSTRUÇÃO DA IDENTIDADE FEMININA
}

\author{
Tatiana Paula Leal Bernardes ${ }^{1}$ \\ Leandro Garcia Rodrigues ${ }^{2}$
}

Resumo: A memória, por ser um processo que se constrói coletivamente, de acordo com Maurice Halbwachs (2006), pode ser usada na construção da identidade de determinados grupos. Tal construção representa pontos positivos, como a identificação com aspectos característicos das sociedades, porém, pode ser também prejudicial. Exemplo disso são as memórias de mulheres, principalmente aquelas periféricas, que estão com frequência à margem da sociedade.

Dessa forma, o livro O feminino e o sagrado, de Julia Kristeva ${ }^{3}$ e Catherine Clément ${ }^{4}$, apresenta situações em que é possível perceber um esquecimento em relação às posições femininas na sociedade, sobre a ótica dominadora, daqueles que detêm o poder de escolha para decidir qual memória será considerada oficial. Assim, é importante analisar tais imposições, uma vez que são prejudiciais e podem levar ao esquecimento de parte da memória cultural de um grupo.

Palavras-chave: Memória coletiva; identidade; feminino; esquecimento.

Abstract: Memory, as a collectively constructed process, according to Maurice Halbwachs (2006), can be used in the construction of identity of certain groups. This construction represents positive points, as identification with characteristic aspects of societies, but can also be detrimental. An example of this are the memories of women, especially those in the periphery, who are often on the periphery of society. Thus, the book O feminino e o sagrado, by Julia Kristeva and Catherine Clément, presents situations in which it is possible to perceive a forgetfulness regarding the feminine positions in society, from the dominant perspective, of those who have the power of choice to decide which memory will be considered official. Therefore, it's important to analyze such impositions as they are detrimental and may lead to the forgetting of part of a group's cultural memory.

Keywords: Collective memory; identity; feminine; forgetfulness.

1 Mestranda em Estudos Literários pelo Programa de Pós-Graduação em Estudos Literários da UFMG. E-mail: tatianapaulaleal@hotmail.com

2 Professor do Programa de Pós-graduação em Estudos Literários da UFMG. E-mail: prof.leandrogarcia@hotmail.com

3 Julia Kristeva é uma filósofa, escritora, crítica literária, psicanalista e feminista búlgaro-francesa. É autora de Séméiotiké. Recherches pour une sémanalyse, de 1969, e de outros textos importantes para a psicanálise e para as análises linguísticas.

4 Catherine Clément é uma escritora, filósofa, crítica literária e ensaísta francesa. É autora de $A$ Senhora, Por Amor da Índia, A Valsa Inacabada, A Rameira do Diabo, A Viagem de Théo, O Último Encontro, As Novas Bacantes, Dez Mil Guitarras, entre outros. 


\section{INTRODUÇÃO}

Vê-se, na sociedade, a memória sendo usada como um instrumento de repressão e de enquadramento social. Isso acontece porque a memória, segundo Halbwachs, é fruto de uma construção coletiva, de modo que é estabelecida de acordo com o que certos setores sociais estabelecem como adequado. O problema desse tipo de enquadramento está no fato de que, devido a essas escolhas, há uma sobreposição de certos grupos, os quais determinam o que deve ser lembrado e o que deve ser esquecido.

Nesse sentido, o presente trabalho tem como objetivo discutir esse enquadramento da memória apresentado no texto de Julia Kristeva e Catherine Clément, O feminino e o sagrado, o qual é formado por uma correspondência das autoras e narra situações em que a memória feminina fica em segundo plano e é reprimida por um grupo social dominante, normalmente composto por homens de classe alta e brancos. Tais fatos narrados no livro mostram como a memória pode ser usada como instrumento de repressão, uma vez que a escolha por determinadas memórias pode levar outras ao esquecimento. É importante discutir sobre esse tema, pois, apesar dos avanços femininos na inserção social, ainda existe uma grande estereotipação em relação a qual espaço pode ser reservado para as mulheres. Assim, esses estereótipos estabelecem uma identidade socialmente aceita do que é ser mulher, algo que não leva em consideração, muitas vezes, os desejos desse mesmo grupo.

Para fazer essa análise, serão utilizados textos referentes à teoria mnemônica e que trabalham a relação da memória com a identidade social e com o esquecimento. Para pensar a construção coletiva da memória, foi escolhido o livro A memória coletiva, de Maurice Halbwachs. Para trabalhar a relação entre a memória e a identidade social que pode ser construída a partir dela, foram usados dois textos: "Memória e identidade social", de Michel Pollak, e "Usos da Memória e do Esquecimento na História", de Enrique Serra Padrós. Além dessas teorias, o presente trabalho pauta-se também no texto de Maria Paula Nascimento Araújo e Myrian Sepúlveda dos Santos, "História, memória e esquecimento: Implicações políticas", o qual discute os efeitos dessa escolha de memória para o esquecimento, focando particularmente nas narrativas orais femininas.

Dessa forma, é importante analisar as relações entre a memória e o esquecimento pautadas nas escolhas de memória feitas ao longo dos anos, as quais, muitas vezes, apagam características de determinados grupos sociais que estão à margem e não são incorporados à memória oficial. Isso é negativo, porque faz com que a sociedade, heterogênea e formada por grupos distintos, perca parte de sua memória cultural.

\section{DESENVOLVIMENTO}

A memória, assim como colocada por Halbwachs, é coletiva e formada pelas relações sociais estabelecidas entre os povos. Halbwachs (2006) afirma que mesmo as lembranças individuais, aquelas que dizem respeito apenas à pessoa envolvida, são coletivas, uma vez que o ser humano é social e pautado em escolhas coletivas. "Isso acontece porque jamais estamos sós. Não é preciso que outros estejam presentes, materialmente distintos de nós, 
porque sempre levamos conosco e em nós certa quantidade de pessoas que não se confundem" (HALBWACHS, 2006, 30).

Para ele, a memória, assim como o esquecimento e a reconstrução de uma lembrança, só é possível se estiver ligada a um grupo, de forma que o afastamento do ser em relação ao coletivo leva a um apagamento.

Nesse sentido, estando a memória sujeita ao coletivo, pode-se afirmar que ela também está em constante mudança, pois acompanha as transformações sociais. Essas transformações estão diretamente ligadas a certas instâncias sociais. Michael Pollak, em seu texto Memória e identidade social, de 1992, afirma que os elementos constitutivos da memória são os acontecimentos pessoais, aqueles que concernem apenas ao indivíduo, e os acontecimentos "vividos por tabela". Estes últimos são eventos coletivos, dos quais o grupo participou e que impactaram o imaginário popular, de forma que passam a ser parte da memória individual, apesar de serem acontecimentos coletivos. Essa memória, segundo Pollak (1992), pode ser considerada uma memória herdada. Além desses acontecimentos individuais e coletivos, Pollak (1992) afirma também que a memória se dá pela construção de personagens, muitas vezes consideradas históricas, e de lugares, e aqui pode-se citar o estudo de Nora (1984), sobre os lugares de memória.

Porém, devido a essa construção coletiva da memória, alguns grupos, considerados minoritários, não são abarcados, o que pode levar a um apagamento das memórias desses setores sociais. Isso é algo preocupante, uma vez que a memória, justamente por seu caráter coletivo, deve ser construída de forma que todos os componentes da sociedade sejam considerados, para que não haja uma escolha por determinados discursos. Pollak (1992) afirma que

[e]sse último elemento da memória - a sua organização em função das preocupações pessoais e políticas do momento- mostra que a memória é um fenômeno construído. Quando falo em construção, em nível individual, quero dizer que os modos de construção podem tanto ser conscientes como inconscientes. O que a memória individual grava, recalca, exclui, relembra, é evidentemente o resultado de um verdadeiro trabalho de organização. (POLLAK, 1992, 4-5)

Essa afirmação de Michael Pollak deixa claro o caráter de construção da memória, de forma que há uma escolha pelo que gravar e pelo que deixar ser esquecido. Essa construção também está presente nas imagens sociais sobre determinados grupos. O próprio indivíduo, ao ignorar certas características pessoais, escolhe aquilo que deseja mostrar à sociedade, reconstruindo, em diversos momentos, a sua identidade frente ao coletivo. Isso também acontece na coletividade. A sociedade, composta de grupos heterogêneos, escolhe características e recalca outras, criando, assim, identidades coletivas. Dessa forma, ainda segundo Pollak (1992),

[p]odemos portanto dizer que a memória é um elemento constituinte do sentimento de identidade, tanto individual como coletiva, na medida em que ela é também um fator extremamente importante do sentimento de continuidade e de coerência de uma pessoa ou de um grupo em sua reconstrução de si. (POLLAK, 1992, 5) 
A identidade de um grupo, dessa forma, está diretamente relacionada à construção da memória, e por ser um aspecto mutável, está subordinada às decisões dos grupos, muitas vezes privilegiados e que assumem a função de estabelecer o que será considerado para a memória coletiva. Pollak (1992) afirma que há um enquadramento de memória, de forma que aquilo que não está de acordo com as vontades do grupo dominante não entrará no que será considerado como "memória oficial".

É importante pensar, partindo dessa análise da construção da identidade coletiva por meio da escolha de memórias e do apagamento de outras, como isso interfere na construção da identidade feminina, sendo que há um grande esquecimento em relação às características próprias às mulheres ao longo dos anos. Para fazer essa análise, será utilizado o livro O feminino e o sagrado, de Julia Kristeva e Catherine Clément, publicado em 2001, no qual as autoras discutem sobre suas percepções no que diz respeito às religiões e à posição das mulheres em meio ao ambiente sagrado. Os casos relatados pelas autoras neste livro demonstram como algumas características femininas foram apagadas ao longo dos anos, o que levou a uma estereotipação do que é ser mulher e a um espaço social bastante restrito a esse grupo.

Sobre isso, Enrique Serra Padrós, em seu texto "Usos da Memória e do Esquecimento na História", publicado pela revista Literatura e Autoritarismo, afirma que

[d]e fato, a memória é uma construção. Como tal, ela é perpassada, veladamente, por mediações que expressam relações de poder que hierarquizam, segundo os interesses dominantes, aspectos de classe, políticos, culturais, etc. Isto não é produto do acaso, é sim, resultado da relação e interação entre os diversos atores históricos em um determinado momento conjuntural. (PADRÓS, 1991, 81)

É perceptível, de acordo com Padrós (1991), que a memória social, e mais especificamente, aceita social e coletivamente, é uma construção que depende das estruturas sociais e políticas, assim como da posição imposta pelo grupo que estabelece essa memória que pode ser considerada como a "oficial".

Padrós, retomando Le Goff, afirma que há uma contraposição entre duas histórias, uma pautada na memória coletiva e outra que ele chama de científica. (PADRÓS, 1991, 82). Enquanto a primeira se relaciona mais diretamente com os acontecimentos sociais, de forma que há sempre uma retomada do passado no presente, a segunda falseia a memória coletiva, impondo como oficial a memória escolhida pelos grupos dominantes da sociedade. Essa concepção apresentada por Padrós, e por Le Goff, mostra um apagamento da memória de alguns setores sociais, de forma que essas memórias não chegam à oficialização, estando sempre à margem do discurso oficial.

É algo que acontece com as mulheres, como é demonstrado em $O$ feminino e o sagrado. Julia Kristeva, na segunda carta que compõe o livro, afirma o seguinte:

Pois se a vida se transformou no último valor de nossas democracias avançadas, cristãs ou pós-cristãs, como queira, esquecemos que essa sacralidade da vida tem uma história; e que essa história depende do lugar que as religiões e as sociedades determinaram para as mulheres. (CLÉMENT, KRISTEVA, 2001, 20) 
Na afirmação de Kristeva, percebe-se que a sociedade escolhe qual lugar será atribuído às mulheres dentro do círculo social, sendo que essa escolha está pautada na memória de grupos, nesse caso específico, os religiosos. Dessa forma, há uma imposição do lugar social estabelecido para as mulheres, de modo que são impostas, também, ações específicas para esse grupo.

Nesse sentido, a memória escolhida para as mulheres age na formação de um estereótipo, o qual é imposto como parte integrante da construção do ser feminino. Padrós (1991) afirma que

[a] lembrança individual torna-se de domínio público, assumindo os valores, a língua, os traços culturais e as vivências que passam a ser comuns, assim como a elaboração da memória e das novas lembranças. São os indivíduos que lembram, mas são os grupos sociais que determinam o que deve ser lembrado e como deve sê-lo. (PADRÓS, 1991, 83)

Da mesma forma como há uma imposição em relação ao que lembrar, há também um esquecimento imposto sobre determinados grupos sociais. Catherine Clément, escrevendo a Julia Kristeva, na $5^{\text {a }}$ carta apresentada no livro, relata sobre mulheres que tinham uma posição social importante e que eram consideradas bastante masculinas. Ela mostra, como exemplo, o caso de Teresa d'Ávila, que era chamada de el padrecito. (CLÉMENT; KRISTEVA, 2001, 43). Uma mulher com a autoridade de Teresa d'Ávila não poderia ser vista como feminina, logo, há uma imposição das características masculinas, a fim de que o indivíduo, no caso Teresa d'Ávila, esteja de acordo com o que foi colocado como correto socialmente. Assim, a memória coletiva em relação à vida de Teresa d'Ávila está totalmente relacionada ao masculino. Nesse caso, percebe-se uma clara escolha de memória, impondo um esquecimento à parte feminina de Teresa d'Ávila, algo que repercute na memória coletiva, sendo reflexo da sociedade, a qual atribui as características de liderança e autoridade apenas aos homens.

Na situação relatada sobre Teresa d'Ávila, é possível perceber que a parte feminina da memória sobre a religiosa foi reprimida. Padrós (1991) afirma que essas memórias que não são levadas em consideração pelo grupo dominante podem ser consideradas como memória subterrâneas.

Na disputa pelo o quê lembrar, é possível pensar em memórias subterrâneas, que surgem e se mantêm nos interstícios dos espaços compreendidos entre o esquecimento e a memória social. Elas expressam as memórias dos excluídos, dos esquecidos da memória oficial. (PADRÓS, 1991, 85)

Dessa forma, pode-se afirmar que as memórias de mulheres são, muitas vezes, esquecidas da memória oficial, podendo ser consideradas como memória subterrâneas, uma vez que existem, mas não são incorporadas ao discurso oficial.

Porém, essas memórias consideradas subterrâneas continuam acontecendo, porque os indivíduos continuam agindo em conformidade com a coletividade. Maria Paula Nasci- 
mento Araújo e Myrian Sepúlveda dos Santos afirmam no texto "História, memória e esquecimento: Implicações políticas", publicado pela Revista Crítica de Ciências Sociais, que

[a] memória não obedece apenas à razão porque ela também está relacionada, por um lado, a tradições herdadas, que fazem parte de nossas identidades e que não respondem a nosso controle, e, por outro, a sentimentos profundos, como amor, ódio, humilhação, dor e ressentimento, que surgem independentemente de nossas vontades. (ARAÚJO; SANTOS, 2007, 96)

Isso pode ser percebido na primeira carta apresentada em $O$ feminino e o sagrado. Nela, Catherine Clément descreve um ritual sagrado presenciado em um vilarejo chamado Popenguine, próximo a Dacar. Nesse ritual, as mulheres entravam em transe, e o que se verificava era que apenas as jovens negras e de classe baixa se encontravam nessa situação. Em dado momento, Clément relata que um homem se dirige a ela para dizer que aquelas reações eram crises histéricas.

A autora, então, propõe uma discussão em relação à imposição da histeria sobre o ritual sagrado dessas mulheres. Ela afirma que "[n]ão, o que o meu vizinho dignitário expressa é outra coisa: uma recusa, um desconforto. A histeria incomoda menos do que o transe, esse grande segredo da África. " (CLÉMENT, KRISTEVA, 2001, 13). Percebe-se nesse relato de Clément uma escolha, por parte do homem, muito provavelmente pertencente à classe dominante, por uma imposição de um termo que rebaixaria as mulheres que estavam na posição de transe, uma vez que a histeria, nesse sentido, seria relacionada à loucura, algo passado pela cultura popular e incorporado à memória coletiva.

Essa análise é importante, uma vez que o transe relatado por Catherine Clément não é motivado apenas pela razão. Existem questões relacionadas à tradição e aos sentimentos daquelas mulheres que não foram levados em consideração na fala do homem que se dirigiu à autora.

Outro relato muito interessante feito por Clément, ainda na primeira carta endereçada a Julia Kristeva, diz respeito a um caso vivenciado por ela na década de 60. Nessa carta, ela relata uma situação presenciada em um hospital em que uma jovem teve uma crise que poderia se considerar de histeria.

Elas são minoritárias e servas, e caem em transe. Não é preciso ir à África para constatar esse fenômeno. Em Paris, nos anos 60, lembro-me de ter assistido no hospital Sainte-Anne a uma verdadeira crise "histérica", desencadeada involuntariamente pelo dr. André Green, então de plantão. Nesse dia, uma jovem deu-nos o grande espetáculo: uma espantosa acrobacia histérica desempenhada com perfeição, cabeça e pé sustentando o corpo enrijecido, curvado em arco, o espírito fora dali, os olhos distantes, displicente, entregue. Comentário do bom doutor: "Não se vê mais este fenômeno arcaico a não ser entre as bretãs analfabetas quando chegam à cidade pela estação de Montaparnasse. " (CLÉMENT, KRISTEVA, 2001, 15) 
A posição do doutor relatado no caso, o qual associa a crise vivida pela jovem ao analfabetismo, de forma a rebaixar a mulher, mostra, mais uma vez, a imposição de um determinado ponto de vista, nesse caso o do homem, em relação à espiritualidade da mulher. Apesar de ser um evento individual, tal comentário, e aqui pode-se retomar as ideias de Halbwachs (2006), está pautado em um ponto de vista coletivo, estruturado por uma elite dominadora que não permite às memórias subterrâneas um espaço na memória oficial, uma vez que não seria possível que os relatos de mulheres analfabetas e socialmente rebaixadas, como é o caso da bretã apresentada, fossem incorporados à memória oficial.

Há, nesses casos, uma imposição do esquecimento, uma vez que, sentindo-se humilhadas pela fala da elite dominadora, essas mulheres não mais irão relatar suas vivências, assim como não haverá espaço para esses relatos, nem mesmo na história oral, o que fará com que tais situações, tão ricas culturalmente, caiam no esquecimento, perdendo-se assim uma parte da memória cultural de um povo.

Maria Paula Nascimento Araújo e Myrian Sepúlveda dos Santos, retomando as ideias apresentadas por Michael Pollak, afirmam que ele

[...] chamou atenção para os processos de dominação e submissão das diferentes versões e memórias, apontando para a clivagem entre a memória oficial e dominante e "memórias subterrâneas", marcadas pelo silêncio, pelo não dito, pelo ressentimento. Esta clivagem pode aparecer não apenas nas relações entre um Estado dominador e a sociedade civil, como também entre a sociedade englobante e grupos minoritários. São lembranças "proibidas", "indizíveis" ou "vergonhosas" que muitas vezes se opõem à mais legítima e poderosa das memórias coletivas: a memória nacional. (ARAÚJO; SANTOS, 2007, 104)

Concluindo a ideia mostrada por Clément sobre o transe das jovens em Popenguine, pode-se perceber que a autora faz uma associação entre a posição social dessas mulheres e a predisposição ao transe. Ela afirma que

[e]u tendo a deduzir, talvez um pouco apressadamente que elas entram em transe com mais facilidade do que suas patroas. Sim, acredito que a capacidade de chegar ao sagrado pela via fulminante depende positivamente do estado de menoridade, ou da exploração econômica. (CLÉMENT; KRISTEVA, 2001, 17)

Dessa forma, Clément mostra que há uma repressão em relação às mulheres que estão inseridas no contexto de dominação, pois o transe, ou a histeria como posto nos relatos, não é algo socialmente colocado para mulheres de classe alta, sendo reservado apenas àquelas que não possuem instrução e que, portanto, serão excluídas da memória oficial. Ao final dessa carta/ensaio, Clément propõe uma reflexão a Julia Kristeva que relacionaria o sagrado à revolta, mas, para fazer essa proposta, ela usa a expressão "uma primeira pista, apagada pelos séculos" (CLÉMENT; KRISTEVA, 2001, 17). Nesse caso, é interessante analisar como as opressões vividas por essas mulheres são excluídas dos discursos oficiais, o que faz com que tais características sejam, assim como colocado por Clément, apagadas pelos séculos. 
Outro ponto muito interessante a se pensar em relação à colocação da mulher e ao apagamento dela frente às posições sociais sagradas é que a Igreja católica, durante muitos anos, considerou as mulheres sem alma, algo relatado por Kristeva, na página 82, de $O$ feminino e o sagrado. Dessa forma, o ser sem alma não poderia ser consultado para a tomada de decisões sociais, algo que excluiu as mulheres das obras divinas e, consequentemente, sociais, uma vez que a Igreja e o Estado eram fortemente associados.

Sobre os trabalhos de Silvia Salvatici, Maria Paula Nascimento Araújo e Myrian Sepúlveda dos Santos afirmam que ela publicou dois trabalhos "Memórias de gênero: reflexões sobre a história oral de mulheres" e "Narrativas de violência no Kosovo do pós-guerra" (Salvatici, 2005a e 2005b). Elas afirmam que,

[n] os dois trabalhos, altamente complementares, Silvia aponta para uma questão importante: o aporte novo e revelador trazido pelos depoimentos femininos para a construção da narrativa histórica. Silvia sublinha o fato de que o campo da história oral e o da história das mulheres se desenvolveram juntos e incentivando-se mutuamente. Ambos nasceram da preocupação de resgatar aquilo que não tinha registro histórico e que, na maioria das vezes, se apoiava apenas no testemunho e no depoimento oral para ser lembrado e conhecido. Tanto um campo quanto o outro teve a preocupação de resgatar esta "voz do passado" e dar-lhe um lugar na história. Para os pesquisadores da história oral e da história das mulheres esta era uma preocupação política, militante. (ARAÚJO; SANTOS, 2007, 105-106)

Dessa forma, percebe-se no trecho citado que a memória de mulheres, principalmente das inferiorizadas socialmente, fica à margem do registro histórico oficial, pois está mais ligada à oralidade e aos registros informais, sendo dessa forma, mais facilmente esquecida. As autoras também afirmam, no final desse trecho destacado, que essa preocupação em relação à história oral e à memória de mulheres é política, sendo então, de ordem social e coletiva.

Logo, percebe-se que a imposição feita a mulheres, em relação a aspectos que são considerados como constitutivos da identidade feminina, é muitas vezes resultado de uma exclusão desse grupo da memória oficial, deixando-o subterrâneo, de forma que as memórias dos componentes desses grupos são esquecidas. Há uma imposição do esquecimento, levando a uma perda da memória cultural.

Maria Paula Nascimento Araújo e Myrian Sepúlveda dos Santos concluem também que

[...] a intenção de entrelaçar interpretações diversas sobre história, memória e esquecimento teve como objetivo mostrar que há várias formas de lidar com o passado e que todas elas envolvem interesse, poder e exclusões. A política da justa memória precisa se equilibrar entre a obsessão pelo passado e as tentativas de imposição do esquecimento. (ARAÚJO; SANTOS, 2007, 109)

Essa posição colocada pelas autoras como justa memória diz respeito a uma maior possibilidade de participação dos grupos minoritários nessa memória oficial, de modo que 
não haja uma imposição do esquecimento e uma escolha de determinadas memória em detrimento daquelas consideradas subterrâneas.

\section{CONCLUSÃO}

Nesse trabalho, foi possível perceber como a memória se relaciona diretamente com a construção da identidade, especificamente, feminina, uma vez que, sendo trabalhada coletivamente, a memória apresenta um caráter também repressor. Isso é afirmado uma vez que há uma escolha do que se lembrar e do que será deixado para o esquecimento. Esse fato é problemático, pois o esquecimento normalmente se dá apenas para os grupos marginalizados socialmente, os quais não têm espaço nas decisões sociais e políticas e que, portanto, não terão espaço na memória oficial.

No livro apresentado como fonte principal de pesquisa para este trabalho, são mostrados casos de mulheres que tiveram suas experiências alteradas pelo olhar de um outro, que não estava diretamente relacionado ao acontecimento. Isso demonstra como uma elite dominante subjuga a memória de outros grupos sociais, os deixando ainda mais marginalizados.

Dessa forma, é importante pensar nas estruturas sociais estabelecidas por essa escolha de memória que impõe um esquecimento e que leva à perda de parte da memória cultural de uma sociedade. 


\section{REFERÊNCIAS BIBLIOGRÁFICAS}

ARAÚJO, Maria Paula Nascimento; SANTOS, Myrian Sepúlveda dos. História, memória e esquecimento: Implicações políticas. Revista Crítica de Ciências Sociais, n. 79, p. 95-111, dez. 2007.

CLÉMENT, Catherine. KRISTEVA, Julia. O feminino e o sagrado. Tradução de Rachel Gutiérrez. Editora Rocco. Rio de Janeiro, 2001.

HALBWACHS, Maurice. A memória coletiva. Tradução de Beatriz Sidou. São Paulo: Centauro. 2006, $224 \mathrm{p}$.

NORA, Pierre. Les lieux de mémoire. I La république. Gallimard, 1984.

PADRÓS, Enrique Serra. Usos da Memória e do Esquecimento na História. Letras, n. 22: Literatura e Autoritarismo, Santa Maria/RS, p. 79-95, jan./jun. 1991.

POLLAK, Michael. Memória e identidade social. Estudos Históricos, v. 5, n. 10, Rio de Janeiro, p. 200$212,1992$.

SALVATICI, Silvia. Memórias de gênero: reflexões sobre a história oral de mulheres. In. História Oral, Revista da Associação Brasileira de História Oral. V. 8(1), p. 29-42. 2005a.

SALVATICI, Silvia. Narrativas de violência no Kosovo do pós-guerra. In. História Oral, Revista da Associação Brasileira de História Oral. V. 8(1), p. 115-127. 2005b. 